\title{
Investigating the Practice of Television Branding: An Afterword on Methodology
}

\author{
SAM WARD, University of Nottingham \\ Journal Editor
}

\begin{abstract}
In this afterword, the editor of Networking Knowledge concludes the current issue by considering some of the methodological questions, problems and innovations that are raised by the preceding articles. With a view to provoking further thought and contributions on the complex and fastdeveloping subject of television branding, it describes two fundamental methodological requirements. Firstly, it argues that branding itself must be treated as a collaborative and fluidly defined industrial practice that is reliant on a relational network of various companies, professions and individual workers. Secondly, given that no television brand exists solely on television a fundamentally transmedia scope of analysis is necessary, not just for effective critical analysis of the 'finished' brand text, but to properly understand that underlying practice. By discussing some of the author's (more and less successful) experiences of trying, as a junior academic, to get to grips with the practice of television branding, this piece considers the practical and epistemological obstacles and opportunities presented by engagement with industrial professionals on the level of their everyday work and self-identity.
\end{abstract}

On a summer morning in 2013 a conspicuous new statue was erected in London's Hyde Park. Among the swans and morning swimmers in the park's Serpentine lake, a 12-foot sculpture emerged, resembling the partially dressed, dripping wet Mr Darcy as played by Colin Firth in the famous scene in which he bumps into Jennifer Ehle's blushing Elizabeth Bennett in the 1995 miniseries adaptation of Pride and Prejudice (BBC/Chestermead). The statue - complete with floppy wet shirt and sideburns - was intended to mark the launch of a new television channel named Drama by broadcaster UKTV. PR firm Taylor Herring had been contracted to create the launch campaign, and they had begun by conducting an audience survey to find the country's most iconic TV moment. The emergence of Darcy/Firth from the lake came first on the list and gave them their launch stunt, which tapped into UKTV's pre-existing overall brand image as the source of unapologetically retro repeats of old drama and comedy content. While their other channels had in fact moved into new and more expensive content in recent years, this new one would serve as a dedicated outlet for such classic series as Pride and Prejudice alongside many others. The erection of the statue resulted in a national news story, with the channel head and the statues' designer both giving interviews to web reporters, while Mr Darcy went on, as part of a 'branded partnership' with the National Trust, to tour other watery locations around Britain, including Lyme Park in Cheshire where the scene in question was shot (see Taylor Herring n.d.). 
On the face of it, this might look simply like a good old-fashioned publicity stunt. ${ }^{1}$ But in the context of an exceptionally competitive multi-channel digital television industry, the crowds who would see the sculpture were insignificant in comparison to the level of recognition that a new channel must hope to achieve in order to survive. Like more and more promotional activities undertaken by television companies, this was part of a transmedia campaign to build a distinct and robust brand for the channel. It jokingly re-purposed a single narrative moment from canonical literature, reconstructing it via its pre-digital televisual presentation, in order to express the identity of a new channel in 2013. The sculpture's tongue-in-cheek boldness thus loudly evoked the celebratory recycling of UKTV's 'golden oldie' content via 'boutique' channel-brands, that are unmistakably part of the multi-channel era of plenty (see Kompare 2005). Meanwhile, the stunt was, of course, intended to be witnessed by many more people online than in person. It was purposefully lacking in any visible evidence of the channel-brand behind it, intended to 'maximise intrigue and media pick up' (Taylor Herring n. d.), so that it couldn't accurately be called an 'advertisement' as such, but an exercise in projecting and sustaining the communication of brand values associated with the light-hearted but literary tone, fannish adoration, and camp, retro sensibilities suggested by the stunt. Numerous pieces in the online press and on the channel's own website were accompanied by video clips of the statue, which, in turn, hyperlinked viewers to YouTube clips of the scene itself (and other related programmes), as well as interaction with other interested viewers (on such 'brand sociality' made possible by the Internet see Arvidsson 2006, 104-14). Photos of the sculpture were tweeted widely by curious Londoners in the run-up to the channel's launch, amounting to 37.9 million Twitter impressions in seven days, putting it among the global top ten trends (Taylor Herring n. d.). When the campaign won a number of awards in the following months, UKTV staff were able to prolong the joke well into the channel's first year, tweeting things like 'Oh Mr Darcy, you've done it again!', and, incidentally, using the opportunity to post new photos of their latest stunt, involving a giant hedgehog on Clapham Common. All this worked to encourage and frame the potential viewer's eventual engagement with UKTV and the channel itself. This brought them back to texts like the one from which Darcy had been lifted, but with a whole range of additional meaning now in tow, which a simple on-air appointment-to-view advertisement for that particular programme would never have produced. Furthermore, none of that meaning originated on the channel itself, and much of it was produced by a range of unknown and un-credited personnel - researchers, designers, sculptors, press and channel staff, not to mention members of the public.

In comparison with the more conceptually and textually adventurous means by which television branding has been done in the examples raised by the articles in this issue, the statue of Darcy might seem technically crude and somewhat incongruous. But I raise it to suggest that, even when multimedia conglomerates, Internet partnerships and social media aren't being proactively and explicitly utilised, and even when there is no specific original content at its heart, television branding today is, in essence, a transmedia practice. By way of drawing a conclusion to the various discussions in the articles above, I want to explore here some of the methodological issues that their common theme has raised for me, as a postgraduate researcher interested in contemporary television branding.

Each of the case studies covered in the issue involves a complex intermingling of various aspects of production and consumption that have all too often been treated as largely separate, throwing up

\footnotetext{
${ }^{1}$ UKTV have made a name for their audacious promo stunts, including the temporary opening of 'Hotel Alcatraz' in London to mark their acquisition of J. J. Abrams-produced Alcatraz (Bad Robot/Warner Bros. Television, 2012). This was a fully functional hotel, built as a replica of the titular San Francisco prison in which members of the public could stay during March 2012 (see Bridge 2012).
} 
hyphenated figures that are just beginning to be properly accounted for. The author-brand, the storyworld-brand, the programme-brand, narrative branding, brand narratives and brand flow are all offered as conceptual lenses via which we can examine the transmedia extension of television branding. In Leora Hadas's study of Joss Whedon's unifying presence over the Marvel universe, branding is shown in close collaboration with the construction of the authorial persona. The articles by Melanie Bourdaa and Erin Giannini, meanwhile, show how the function of transmedia storytelling goes beyond the merely narrative, being a fundamental aspect of the overall company brands and funding streams of, respectively, a producer-distributor and a national network. Matthew Freeman adds a historical view to this discussion, with his look at how cinema-television crossovers rely on a visual synergy that works fundamentally according to the logic of branding. It is highly useful that each article focuses its conceptual discussion around a concrete example, as it is otherwise tempting to theorise loosely on these difficult and inter-connected concepts in order to sidestep the inconvenience of complexity that they present. The importance of such empirical evidence, however multi-layered and lacking in conclusive patterns, is summed up by the simple but crucial fact that is posed by the title of Benjamin Derhy Kurtz's editorial introduction to this issue: that branding is, before anything else, a practice - not static like a finished 'text', but a composite and collaborative process that is highly contingent and fluid, defined by both creative and business imperatives, the only aim that really stays the same over time being adaptability in a fast-changing and competitive environment. While looking directly at the texts that make up a brand is surely an important aspect of getting to grips with examining its workings, epistemologically speaking this can only take us so far when there is a great deal going on behind the scenes that only appears when we consider branding as a practice. When one asks, say, how a huge conglomerate, with multiple sister companies, working across various media and national territories, involving thousands of personnel, is found to be 'branding' an individual product (not to mention authors or story-worlds), we are basically requiring a detailed look at the day-to-day professional practice of a large network of different personnel, each with their own training background and pressures, who may or may not be pulling in precisely the same direction.

So while the proposition is simple, the methodological implications for reaching solid research findings about branding as a practice are anything but. Accordingly (and inevitably) those concepts I mention and several others suggested by the authors in this issue each throw up more questions than could possibly be answered in these pages. For example, what does it mean for a real-world brand to be built from fictional assets - whether it be the image of Gotham City or a mock vampire beverage? Who decides what counts as 'branding' when the traditional boundary between 'creative' and 'marketing' are seemingly less and less meaningful? Can we talk about the 'brand' of something like a programme in the same way as that of, say, a service platform (like Sky), or even a television manufacturer; and what does it mean that industry professionals might use that same word in relation to all these things? How do we distinguish between 'adapted' and 'transmedia' narratives, when we are dealing with examples that cannot be easily grouped either with a Jane Austen mini-series or with The Matrix (1999, Andy and Lana Wachowski)? And at what point does 'television' have to be called into question as a delimited object of study when content is diegetically, narratively, promotionally or institutionally interlocked with that of websites, cinema screens, comics, fan conventions, or, indeed, a plastic statue in a London park?

Of course, the complexities presented by these questions aren't entirely new. In a sense television branding has always been an innately transmedia phenomenon. If branding essentially works to embellish content - whether individual programmes or larger sets under one channel or strand giving it value associations and adding layers of narrative identity beyond its textual limits, 
television branding has historically never been restricted to the televisual medium. Indeed, we might consider that the brands of the original television networks in the US had already been developed throughout their prehistory as radio channels (and Michele Hilmes $(2007 ; 2011)$ among others have argued for the importance of radio in understanding television's industrial practices). Scholars like Avi Santo (2010) have also shown that the licensing of merchandising first saw storyworlds being extended - at least in consumer's imaginations - beyond the televisual text at least as far back as the middle of the twentieth century. As Freeman argues in his contribution here (which serves as an appropriate companion to Santo's discussion of Batman merchandising in the 1960s), television branding has worked in proactive and intricate ways across different media before the digital technology of the contemporary setting made a truism of the fact that no television brand exists solely on television (see Johnson 2012, 37-59).

Therefore, as amply reflected by the bibliographies for all of the articles here and many other works on television branding, in order to properly study the topic we must inevitably approach it with a transmedia scope. For anyone starting out on a research project that has anything to do with the television industry, this is a methodological commonplace. For me at least, the first place to go to get a feel for a television brand is not my television set, but a website, the latter offering a far more concentrated, explicit and readily accessible source of evidence than the programming flow of the on-air channel. Every channel or network has a website, of course, and they are often huge, comprised of numerous pages for individual shows, which will themselves often have separate, dedicated websites elsewhere. At the same time experiencing television brands is not just limited to screens, as content, channels and service providers are also promoted on bill-boards, bus-stops and the pages of newspapers and magazines. And of course, what is being promoted is more and more often not delivered simply via a television set, as at least since the 1990s media conglomerates have found added value in, to use Freeman's phrase, 'encourag[ing] the transmediated consumption of a storyworld'.

This can all amount to a bewildering challenge in researching television brands, not simply because in the Internet age it represents an expansive (and always expanding) work-load for the scholar, but because television companies, too, are faced with that same expansive and crowded field across which they have to communicate a coherent and, ideally, dominant brand message. Given Mark Deuze's point that 'the professional identity of media workers is still negotiating an answer to convergence culture' $(2007,236)$, we must remain aware that, taken as a tool used by the media industries, 'transmedia' is itself not consistently defined or applied and is not so much a sure-fire source of success, but more likely one of uncertainty and experimentation. Scholars are therefore charged with disentangling a mass of discourse that television companies throw out, even if its 'success' is not so clear (not to mention the various means by which 'success' might be defined and measured). As Hadas and Freeman both show in their articles, the insertion of authorial personas into this branding discourse leads to yet another level of complexity in relating the work done in the marketing department to that done by the writer or director in creating, as it were, the text itself (Gray 2010, 17). Added to this is the fact that much of the work of branding itself (especially for smaller or syndication-reliant television companies, such as UKTV) is outsourced and compartmentalised according to the medium (on-air, online or print) and design brief of a particular campaign, which are usually completed to very tight deadlines, are fundamentally collaborative, and go through several layers of editorial filtering before becoming part of the brand presented to consumers. 
Besides the various professionals who work directly on what we might call the brand-text itself, the work of others - whether in production, editorial, content buying, scheduling, or technical work inevitably must be taken into consideration in accounting for the transmedia brand. This brings up the question again of who decides where branding ends and that which is branded begins. This arose starkly when I interviewed a member of the acquisitions staff at UKTV. Being interested in the interaction between programming decisions and a channel's identity, and, as a second-year PhD student, having been steeped in academic literature about branding, I kept asking about 'the brand strategy'. With each mention of the phrase I noticed my interviewee hesitate momentarily, until eventually she asked, 'Why do you say "branding"? It's editorial. It's not a branding decision.' When I pressed her on the precise distinction, she spoke in terms of her day-to-day professional inner monologue:

I would say that editorially [a programme] would fit in with the channel brand. I don't think in terms of branding, I think in terms of editorial. I suppose its semantics: you can say, 'yeah, that fits in with the brand, that fits in with the [channel's] brand'. But it's not a phrase I would use. Ever.

While we must be cautious not to overplay the significance of one interviewee's self-image, this was nevertheless fascinating to me for two reasons. Primarily, the first-hand testament to the negotiation of these various concepts as they circulate and substitute each other within industrial contexts is more interesting than any conclusive definition of what the brand strategy might be (reliant as the latter is by that on-going and subjective negotiation). While, as Brett Mills writes, 'it is important to acknowledge the subjectivity within any interview material, and not to use this data as evidence of certain kinds of working practices' $(2008,152)$, the very fact of how media professionals subjectively talk about and present their practices provides critical insight in itself. As the transmedia strategies described in this issue remind us, when we talk about branding on a transmedia level (for that matter, when we talk about any media content) we are talking about an organic, collaborative, fluid network of texts, individual components in which can either enhance or compromise each other (see Freeman's article in particular on this), and which will be subject to numerous different industrial forces (creative, editorial, executive, and so on). This fluidity of the practice is transferred into fixed meaning precisely in the labour of individuals such as this interviewee, and in the way that they think and talk about that labour themselves. That is to say, we might be inclined not to trust her insistence that she doesn't $d o$ branding (and the precise identification of where and when 'branding' happens is as pressing a question as how and why), but we must also take into account the fact that she frames her work as something different.

But secondly, the slippage between 'branding' and 'editorial', of which this interviewee is fully aware, reminds us that, while we can see the branding of television starting to utilise transmedia storytelling, there is also a sense in which 'transmedia' is being made to conform to a certain televisual structure and vocabulary. This particular professional is engaged in selecting imported programming for a particular group of channels, which is essentially a televisual role - content is purchased, and scheduled and the size of its audiences determine the measure of its 'success'. She sees this as 'editorial', suggesting something of the 'old', broadcast logic of distribution bottlenecks and gatekeepers (as well as specifically expressive of the British television system). What the interchangeability that obviously operates between the two terms in question shows is that this 'old' logic is not being replaced, but rather put into co-operation with a new one, embodied by the interviewee's colleagues in the marketing department, against whose work she categorically distinguishes her own and which represents another set of workers with their own professional self- 
identity (see Hackley and Rungpaka Tiwsakul 2011). This is, of course, just one interview with one member of staff with a specific role within the company (and I don't have space here to go into all the various personnel who impact on the practice of branding in this instance ${ }^{2}$ ), but it shows how important and productive it is to take into account how terms like 'branding' and 'transmedia' are operating in industrial circles.

A final element of complexity is added, as touched on by several of the articles here, by the impact of semi- or unofficial texts on the brand itself - whether it be, say, public discussion about the value of a particular channel (see the recent protests over the proposed transformation of BBC Three into a web-only 'channel' - deeply intertwined with matters of brand identification), or a group of bloggers reporting on the latest developments in an online alternate reality game. This, too, could be considered as part of the practice of branding, especially as bloggers, crowdsourcing sites and PR firms are increasingly positioned as institutional intermediaries between media companies and audiences, as in the case of Campfire's dissemination of its 'Tru Blood' campaign that is described by Bourdaa.

This all means that, even with the most well-resourced, well-researched and aggressively delivered television branding strategies we are sure to have to grapple with inconsistencies, changes of tack and sheer anomalous 'noise' when trying to describe a television brand comprehensively. With such multi-faceted and fast-changing strategies it is vital that we identify means to gain a solid, finegrain perspective on the role of transmediality in television branding. One way that my own work has benefited infinitely in this respect is by talking directly to professionals, such as the one quoted above, whose work contributes to those strategies. Television branding - indeed, television as a whole - is done by individuals with job descriptions that are hugely diverse, often intrinsically creative, and directly engaged - to the point that it is taken for granted - with the extension of content across media. Despite the work of marketing editors, creatives in brand design and advertising agencies, and market researchers (just to mention a few) being instrumental in how television brands appear and function, they have barely been studied at length in television studies, or more widely (although see Grainge and Johnson, forthcoming). A recent edition of View: Journal of European Television History and Culture offers a welcome and stimulating first foray into 'the hidden professions of television', but none of the articles there specifically focuses on branding. Importantly, though, the topic is closely connected to several professions that are discussed, such as retailers of television sets (Gaillard 2013) and continuity announcers (de Leeuw and Mustata 2013). There, too, the editors' introduction points out the methodological obstacles that go some way to explaining the lack of attention afforded to the area, namely the problem of 'researcher's access to backstage activities and to work documents that have remained undisclosed to outsiders' (O'Dwyer and O'Sullivan 2013, 1). In the case of branding, this question of access to the processes and decision-making is especially difficult. This is obviously partly because the success of a brand is by definition reliant of the revelation only of the finished product, and proprietary control is tantamount (in contrast to, say, the production notes and behind-the-scenes material that now readily makes up the promotional surround of a programme). Moreover, as I have said, that process commonly involves a huge amount of inter-departmental and inter-business interaction, which is on-going, often unrecorded and usually subject to either formal or assumed confidentiality agreements. This presents a challenge, but also a crucial point of curiosity for any scholar interested in understanding television branding - that is, attendant with the increasing focus on interactive and transmedia strategies, television branding is essentially a product of the

\footnotetext{
${ }^{2}$ For a detailed look at UKTV's channel-brands in the early twenty-first century, see Johnson 2012, 76-78.
} 
interaction between media businesses, emerging from the creative labour of intermediaries whose names are never seen by audiences in the credits.

But despite these obstacles, it should not be assumed that a company's commercial self-interest will always make engagement with academics an impossibility. In fact, just in my modest experience as a post-graduate researcher looking to find out about the work that goes into channel-branding in the UK, I have been surprised by how open and intrigued some of my own interviewees have been when asked to talk about their work. When I visited one major UK broadcaster to talk to a member of their marketing team, after being given a tour of their open-plan offices, the interviewee presented a tantalising pile of documents that I had until then presumed would be the kind of thing that was entirely off limits for an outsider. There were no especially sensitive details included and we had a conversation about how I might make use of the documents, agreeing that I would check with the company if I planned to cite anything directly. When it became clear that I wasn't too interested in any financial figures or information that the company's competitors might prize, but rather the very workings and lay-out of many of the documents on a quite basic level, the participant was happy to discuss them at length. He was pleased - and perhaps a little bemused that I was interested in the nuts and bolts of his daily work, and talked me through each document's relation to his own work. Many of the documents offered information on the practice of branding that I would never have gained had I not engaged directly with that individual, all being intended for internal use: a report by a market research contractor on the success and 'hygiene' of their channel-brands; colour-coded schedule plans that visually highlighted shows that were deemed 'flagship'; image-based distillations of the channels' brand 'propositions'; and the project brief for a design company who had won the contract to rebrand one the company's channels.

At the institutional level, this kind of engagement is being facilitated by the emerging sub-field of media industry studies. This obviously involves a whole range of subject matter, which overlaps and intersects with several other sub-fields, and I don't have space to go into them all here (but see McDonald et al 2013 and Holt and Perren 2009 for some of the ways this approach can be applied). What I am more interested in, not least as a trainee academic looking for an innovative and fulfilling career path, is the practical and institutional conditions in which this work can be negotiated, supported and made adaptable to the ever-changing media landscape. The University of Nottingham's Institute for Screen Industry Research is a good example of academia-industry exchange, offering mutual benefits to academics and media organisations alike. The more such initiatives are created - and the more they can be extended to tomorrow's academics to develop innovative and rigorous research projects - the better, if we are to be fully sensitive to the challenges, changes and opportunities that things like transmedia branding represent for television.

I have suggested here just a few of the ways in which television branding shows itself to be characterised when we approach it as a) a function of professional practice, and b) one that is essentially always already transmedia. It is a fluid and contingent process, making its end product (the branding text itself, we might say) only one aspect of the picture; it is interconnected with several other industrial spheres, with marketing at the core of many companies' operations in this transmedia environment; and it is professionally multi-disciplinary, both producing and operating within an intensely relational industrial culture. Furthermore many of the professions and kinds of business this aspect of media production involves have been sorely under-studied. In a sense, one useful way to situate branding as an object of study - and to remove it from the limits of a mediumspecific approach, as this issue has proposed - is as a membrane between textuality and industry. It 
is an essentially industrial activity, but is at the same time an undeniably imaginative and multipurpose one, producing what are arguably the most semiotically and authorially complex of all media texts. When branding 'goes transmedia', it is primarily because presence on more than one medium means increased audience penetration. But it also allows a more sophisticated melding and fluidity between narrative iterations with the means of selling the original fictional narratives. The theorisation of this fluidity - both between narrative and marketing texts, and between various media forms - is only just beginning to accrue a common set of conceptual touch-points. The keenly focused and challenging work that Derhy Kurtz has gathered in this issue offer timely steps in finding our methodological feet in studying this key industrial practice.

\section{References}

Arvidsson, A. (2006) Brands: Meaning and Value in Media Culture, Abingdon, Oxon: Routledge

Bridge, A. (2012) 'One Night in Alcatraz', Telegraph.co.uk, Travel, 13 March. Accessible at http://www.telegraph.co.uk/travel/hotels/9140495/One-night-in-Alcatraz.html. Accessed 31 March 2014

de Leeuw, S. and Mustata, D. (2013) In-Vision Continuity Announcers: Performing an Identity for Early Television in Europe', VIEW: Journal of European Television History and Culture, 2(4), 51-67. Accessible at http://viewjournal.eu/index.php/view/article/view/JETHC044/87. Accessed 1 April 2014

Deuze, M. (2007) Media Work, Cambridge: Polity

Gaillard, I. (2013) 'An Unknown, but Key Player in the Television Market: The Television Retailer and the Case of Black and White TV Sets in France (1950-1987)', VIEW: Journal of European Television History and Culture, 2(4), 79-88. Accessible at http://viewjournal.eu/index.php/view/article/view/JETHC046/83. Accessed 1 April 2014

Grainge, P. and Johnson, C. (forthcoming), The Promotional Screen Industries, London: Routledge

Gray, J. (2010) Show Sold Separately: Promos, Spoilers, and other Media Paratexts, New York: New York University Press

Hackley, C. and Rungpaka Tiwsakul, A. (2011) 'Advertising Management and Professional Identity in the Digital Age', M. Deuze (ed.), Managing Media Work, London: Sage, 209-15 Hilmes, M. (2007) (ed.) NBC: America's Network, Berkeley: University of California Press --- (2011) Only Connect: A Cultural History of Broadcasting in the United States, $3^{\text {rd }}$ edition, Boston, MA: Wadsworth

Holt, J. and Perren, A. (2009) Media Industries: History, Theory, and Method, Malden, MA: Wiley-Blackwell

Johnson, C. (2012) Television Branding, Abingdon, Oxon and New York: Routledge

Kompare, D. (2005) Rerun Nation: How Repeats Invented American Television Routledge: New York 
McDonald, P. (2013) (ed.) 'In Focus: Media Industries Studies', Cinema Journal, 52(3), 145-89

Mills, B. (2008) 'After the Interview', Cinema Journal, 47(2), 148-53

O'Dwyer, A. and O'Sullivan, T. (2013) 'Editorial', VIEW: Journal of European Television History and Culture, 2(4), 1-2. Accessible at

http://viewjournal.eu/index.php/view/article/view/JETHC039/100. Accessed 1 April 2014

Santo, A. (2010) "Batman" versus "The Green Hornet": The Merchandisable TV Text and the Paradox of Licensing in the Classical Network Era', Cinema Journal, 49(2), 63-85

Taylor Herring (n. d.) 'Oh Mr Darcy! Giant Mr Darcy Mark Launch of Drama Channel', TaylorHerring.com. Accessible at http://www.taylorherring.com/case-studies/mrdarcystunt/. Accessed 31 March 2014 